\title{
Variant Creutzfeldt-Jakob Disease:
}

\author{
French versus British
}

Wen-Quan Zou, MD, PhD and Pierluigi Gambetti, MD

Institute of Pathology, National Prion Disease Pathology, Surveillance Center, Case Western

Reserve University, Cleveland, $\mathrm{OH}$

The history of the transmissible spongiform encephalopathies or prion diseases is teeming with dramatic findings. Originally described as neurodegenerative conditions, these diseases were shown to be experimentally transmissible to animals; subsequently, human-to-human transmissibility through the tribal custom of cannibalism or through medical procedures was reported. ${ }^{1-4}$ Then in 1996, with the discovery of variant Creutzfeldt-Jakob disease (vCJD), prion diseases assumed renewed and dangerous relevance. ${ }^{5}$ The appearance of vCJD followed a prion disease epidemic named bovine spongiform encephalopathy (BSE) in cattle, and it was clear that VCJD was caused by the consumption of prion-contaminated meat from BSE-affected cattle. ${ }^{6-8}$ Prion diseases thereby proved themselves capable of jumping the species barrier and of being naturally transmissible from animals to humans. Originally discovered in the United Kingdom, vCJD has subsequently been reported in other countries but especially in France. In this issue of the Annals of Neurology, Brandel and colleagues ${ }^{9}$ present a detailed comparison between the clinical, histopathological, and prion-protein (PrP) characteristics of the VCJD identified in France and in the United Kingdom.

Human prion diseases include three major forms. One form encompasses prion diseases that are acquired through infection including vCJD, kuru of New Guinea, and iatrogenic CJD. The other two forms comprise sporadic CJD, the most common form of human prion diseases, and the genetically determined or familial CJD. However, regardless of their form, all prion diseases share a fundamental and identical pathogenetic mechanism: the conversion of the normal or cellular $\operatorname{PrP}$ into an isoform, identified as scrapie $\operatorname{PrP}\left(\mathrm{PrP}^{\mathrm{Sc}}\right)$, which is insoluble in detergent, often resistant to protease, and pathogenic. ${ }^{10}$ Another typical characteristic of prion diseases is that they are recognizable and can be compared with each other based on two major molecular features: the physicochemical, especially electrophoretic, characteristics of $\mathrm{PrP}^{\mathrm{Sc}}$, which largely define the so-called prion strain, and the genotype of the patient based on the methionine/valine polymorphism at codon 129 of the PrP gene. ${ }^{6,11,12}$ These two features are crucial in distinguishing between the types of prion diseases and their respective origins. ${ }^{6,8}$,

${ }^{12}$ For instance, through these features, it has been shown that the electrophoretic characteristics of $\mathrm{PrP}^{\mathrm{Sc}}$ associated with vCJD observed in the British patients are similar to those of $\mathrm{PrP}^{\mathrm{Sc}}$ associated with the British BSE, from which it can be inferred that the former originated in the latter. ${ }^{6,8}$ This conclusion has been supported by the transmissibility experiments, which provided overwhelming evidence that VCJD is an acquired, not a spontaneous, human disease. 6-8 The comparative analyses of the British vCJD with other prion diseases have also been facilitated by the clinical and histopathological characteristics of vCJD, which are homogeneous yet highly differentiated from those of other known human prion diseases. ${ }^{13}$ 
Brandel and colleagues' ${ }^{9}$ study uses all these points of reference to show that the British and French vCJD cases manifest similar clinical, histopathological, and molecular features, from which it can be confidently concluded that the two vCJD sets of patients share the same $\mathrm{PrP}^{\mathrm{Sc}}$ isoform or strain. ${ }^{9}$ The clinical disease duration is also similar. The only major divergence emerging from this study appears in the age at onset, which is more than 8 years older in the French than in the British cases ( 36.4 vs 28.3 years). This difference may stem from an average exposure to lower amounts of BSE PrPSc in the French patient population (because of different dietary habits), as the authors suggest, ${ }^{9}$ or from greater dilution of $\mathrm{PrP}^{\mathrm{Sc}}$ in the meat consumed by the French patient population. Reduced exposure would explain the longer incubation time.${ }^{14}$ However, other possibilities, such as a slight change in the French prion strain, cannot be ruled out. The finding that the duration of the symptomatic disease is similar agrees with the experimental transmission data, which likewise demonstrated that the clinical disease duration is not related to incubation time. ${ }^{15}$

Brandel and colleagues' ${ }^{9}$ findings bring back to the fore at least two issues. First, it raises the question of the origin of the infectious prion in the French vCJD: whether it originates from British BSE or from indigenous French BSE; second, whether vCJD worldwide is caused by one prion strain or whether all vCJD cases carry the same British prion strain. It is critical that these two issues be clarified so that the spread of the BSE epidemics through different continents can be understood and arrested.

Concerning the origin of the prion strain associated with the French cases of vCJD, the broad similarity of the phenotypic and $\mathrm{PrP}^{\mathrm{Sc}}$ characteristics between French and British vCJD cases is consistent with the notion that the French vCJD prion strain derives from the consumption of prion-contaminated beef imported from the United Kingdom. ${ }^{9,16}$ This notion is also supported by the absence of correlation between the prevalence of $\mathrm{vCJD}$ and the incidence of BSE observed in several countries such as Switzerland and Germany, where there is a greater incidence of BSE but no cases of vCJD. ${ }^{17}$ Alternatively, French vCJD might have resulted from indigenous BSE, whereas the $\mathrm{PrPSc}^{\mathrm{Sc}}$ had strain characteristics similar to the British BSE possibly because the prion-infected high-protein diet, the so-called meat and bone meal that triggered BSE in the two countries, had the same characteristics. Either origin is consistent with the 5-year delay in the peak incidence of French vCJD compared with that of British vCJD, as well as the 9-year delay between the peak incidence of the British and French BSE (Table 1). ${ }^{18} \mathrm{~A}$ ban on British beef import was introduced in France and the whole European Union in March 1996. ${ }^{19}$ The origin of the French vCJD from indigenous French BSE would become highly compelling if cases of vCJD were discovered among people born in France after the ban went into effect.

To investigate further the origin of French vCJD, it would be necessary for investigators to conduct a detailed comparative study of the strain characteristics of $\mathrm{PrP}^{\mathrm{Sc}}$ associated with British and French BSE and vCJD using direct analyses and transmissibility studies in transgenic mice expressing bovine PrP, and monitoring incubation time, attack rate, and phenotypic characteristics of the transmitted diseases.

Similar studies extended to the BSE and vCJD observed in other countries around the world where these two prion diseases have been reported (Table 2) may answer the question whether vCJD identified in these countries shares the same prion strain with British vCJD as the French cases likely do. ${ }^{9,20}$ The high homogeneity of the phenotypic and $\mathrm{PrP}^{\mathrm{Sc}}$ characteristics indeed suggests that all cases of vCJD around the world have been caused by a prion strain indistinguishable from that of the British cases.

Although the incidence of VCJD and BSE has been decreasing after the epidemic, Brandel and colleagues study, ${ }^{9}$ together with other studies mentioned earlier, as well as the continuing 
reporting of new cases, all clearly indicate that the battle against vCJD and BSE is far from over.

\section{References}

1. Gordon WS. Advance in veterinary research. Vet Res 1946;58:516-520.

2. Chandler RL. Encephalopathy in mice produced by inoculation with scrapie brain material. Lancet 1961;1:1378-1379. [PubMed: 13692303]

3. Gajdusek DC, Gibbs CJ Jr, Alpers M. Experimental transmission of a Kuru-like syndrome to chimpanzees. Nature 1966;209:794-796. [PubMed: 5922150]

4. Duffy P, Wolf J, Collins G, et al. Possible person to person transmission of Creutzfeldt-Jakob disease. N Engl J Med 1974;290:692-693. [PubMed: 4591849]

5. Will RG, Ironside JW, Zeidler M, et al. A new variant of Creutzfeldt-Jakob disease in the UK. Lancet 1996;347:921-925. [PubMed: 8598754]

6. Collinge J, Sidle KCL, Meads J, et al. Molecular analysis of prion strain variation and the aetiology of "new variant" CJD. Nature 1996;383:685-690. [PubMed: 8878476]

7. Bruce ME, Will RG, Ironside JW, et al. Transmissions to mice indicate that 'new variant' CJD is caused by the BSE agent. Nature 1997;389:498-501. [PubMed: 9333239]

8. Hill AF, Desbruslais M, Joiner S, et al. The same prion strain causes vCJD and BSE. Nature 1997;389:448-526. [PubMed: 9333232]

9. Brandel JP, Heath CA, Head MW, et al. Variant Creutzfeld--Jakob disease in France and the UnitedKingdom: evidence for the same agent strain. Ann Neurol 2009;65:250-257.

10. Prusiner SB. Prions. Proc Natl Acad Sci U S A 1998;95:13363-13383. [PubMed: 9811807]

11. Parchi P, Castellani R, Capellari S, et al. Molecular basis of phenotypic variability in sporadic Creutzfeldt-Jakob disease. Ann Neurol 1996;39:767-778. [PubMed: 8651649]

12. Gambetti P, Kong Q, Zou W, et al. Sporadic and familial CJD: classification and characterization. Brit Med Bull 2003;66:213-239. [PubMed: 14522861]

13. Zeidler M, Stewart GE, Barraclough CR, et al. New variant Creutzfeldt-Jakob disease: neurological features and diagnostic tests. Lancet 1997;350:903-907. [PubMed: 9314867]

14. Prusiner SB, Cochran SP, Groth DF, et al. Measurement of the scrapie agent using an incubation time interval assay. Ann Neurol 1982;11:353-358. [PubMed: 6808890]

15. Kong Q, Huang S, Zou W, et al. Chronic wasting disease of elk: transmissibility to humans examined by transgenic mouse models. J Neurosci 2005;25:7944-7949. [PubMed: 16135751]

16. Sanchez-Juan P, Cousens SN, Will RG, et al. Source of variant Creutzfeldt-Jakob disease outside United Kingdom. Emerg Infect Dis 2007;13:1166-1169. [PubMed: 17953086]

17. Chadeau-Hyam M, Alperovitch A. Risk of variant Creutzfeldt-Jakob disease in France. Int J Epidemiol 2005;34:46-52. [PubMed: 15649960]

18. World Organization for Animal Health. [Accessed November 26, 2008]. Available at: http://www.oie.int/eng/info/en_esbincidence.htm

19. Abrial D, Calavas D, Jarrige N, et al. Poultry, pig and the risk of BSE following the feed ban in France —ecological analysis. Vet Res 2005;36:615-622. [PubMed: 15955285]

20. National Creutzfeldt-Jakob Disease Surveillance Unit (NCJDSU). Variant Creutzfeldt-Jakob Disease: current data. Dec2008 [Accessed November 26, 2008]. Available at: http://www.cjd.ed.ac.uk/vcjdworld.htm 
Table 1

Number of Reported Variant Creutzfeldt-Jakob Disease and Bovine Spongiform Encephalopathy Cases in France and the United Kingdom

\begin{tabular}{|c|c|c|c|c|}
\hline \multicolumn{5}{|c|}{ YearFrench vCJDBritish vCJDFrench BSEBritish BSI } \\
\hline 1989 & 0 & 0 & 0 & 7,137 \\
\hline 1990 & 0 & 0 & 0 & 14,181 \\
\hline 1991 & 0 & 0 & 5 & 25,032 \\
\hline 1992 & 0 & 0 & 0 & $36,682^{a}$ \\
\hline 1993 & 0 & 0 & 1 & 34,370 \\
\hline 1994 & 1 & 8 & 4 & 23,945 \\
\hline 1995 & 0 & 10 & 3 & 14,302 \\
\hline 1996 & 0 & 11 & 12 & 8,016 \\
\hline 1997 & 0 & 14 & 6 & 4,312 \\
\hline 1998 & 1 & 17 & 18 & 3,179 \\
\hline 1999 & 1 & $29^{b}$ & 31 & 2,274 \\
\hline 2000 & 1 & 24 & 161 & 1,355 \\
\hline 2001 & 2 & 16 & $274^{a}$ & 1,113 \\
\hline 2002 & 0 & 13 & 239 & 1,044 \\
\hline 2003 & 2 & 4 & 137 & 549 \\
\hline 2004 & $7^{b}$ & 9 & 54 & 309 \\
\hline 2005 & 4 & 5 & 31 & 203 \\
\hline 2006 & 4 & 2 & 8 & 104 \\
\hline 2007 & 0 & 0 & 9 & 53 \\
\hline 2008 & 0 & 0 & 4 & 23 \\
\hline
\end{tabular}


Table 2

Number of Reported Cases of Bovine Spongiform Encephalopathy and Variant CreutzfeldtJakob Disease in the Countries with the two prion diseases

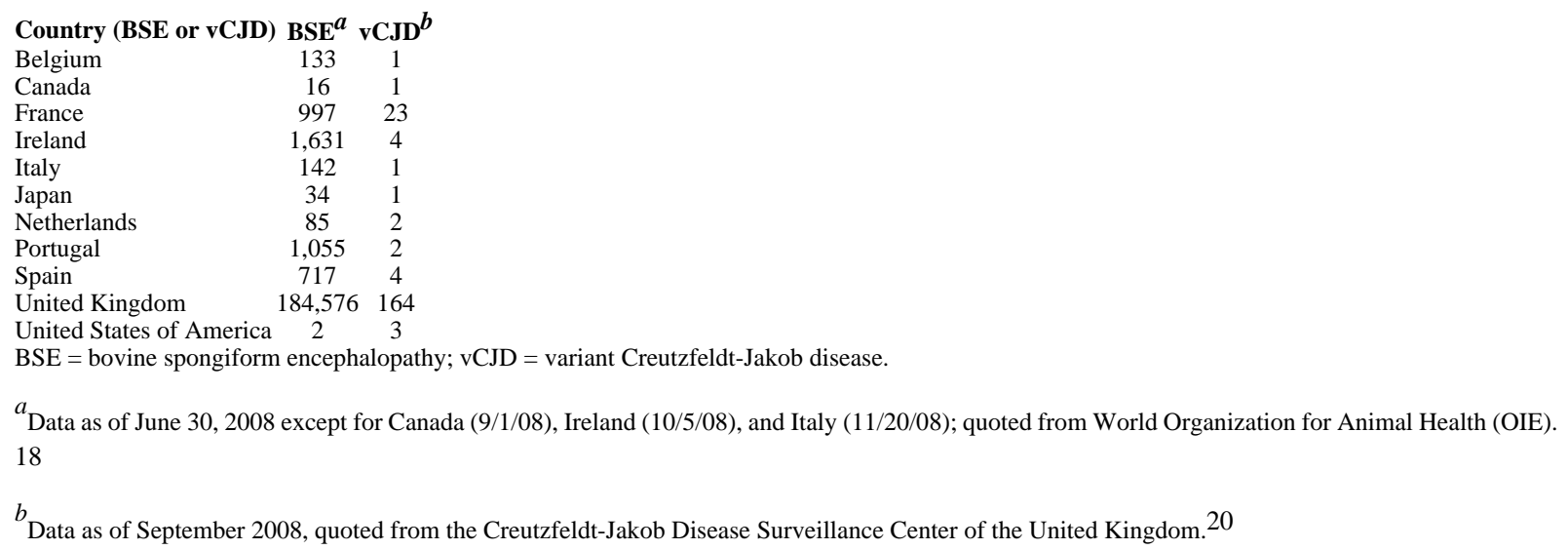

